\title{
FORMAÇÃO E PROFISSIONALIZAÇÃO DOCENTE: UMA PERSPECTIVA DE MUDANÇA
}

\author{
FORMACIÓN Y PROFESIONALIDAD \\ DOCENTE: UNA PERSPECTIVA DE CAMBIO
}

TEACHER EDUCATION AND PROFESSIONALIZATION:

A CHANGE OF PERSPECTIVE

Jose Jailton RIBEIRO ${ }^{1}$

RESUMO: O presente artigo tem como escopo identificar e analisar algumas peculiaridades a respeito da formação e profissionalização de suas práticas docentes. Pretendemos também investigar pressupostos a questão da formação continuada no Brasil, fazer uma explanação a despeito das práticas já utilizadas em épocas anteriores com as atuais e elucidar a importância em se ter uma formação continuada para os docentes. Identificar o perfil que anteriormente era legado ao profissional da educação como um serviço sacerdotal, imposto pela Igreja, analisar o modelo atual de docente no processo de sua formação, interligado principalmente com as novas práticas e diretrizes pedagógicas fundamentando o processo histórico da profissionalização do docente, procurou-se esboçar um perfil ideal de professor, posteriormente a décadas com diversas mudanças sociais ocorridas.

PALAVRAS-CHAVE: Formação docente. Centro de formação. Formação teóricoprática articulada na formação inicial e Educação continuada.

RESUMEN: El presente artículo tiene como objetivo identificar y analizar algunas peculiaridades acerca de la formación y profesionalización de sus prácticas docentes. También pretendemos investigar supuestos a la cuestión de la formación continuada en Brasil, hacer una explicación a despecho de las prácticas ya utilizadas en épocas anteriores con las actuales y elucidar la importancia de una formación continuada para los docentes. Identificar el perfil que anteriormente era legado al profesional de la educación como un servicio sacerdotal, impuesto por la Iglesia, analizar el modelo actual de docente en el proceso de su formación, interconectado principalmente con las nuevas prácticas y directrices pedagógicas fundamentando el proceso histórico de la profesionalización del docente, se intentó esbozar un perfil ideal de profesor, posteriormente a las décadas que presentan diversos cambios sociales ocurridos.

PALABRAS CLAVE: Formación docente. Centro de formación. Formación teóricopráctica articulada en la formación inicial y Educación continuada.

${ }^{1}$ Faculdade Mauricio de Nassau, Estação Velha - Campina Grande - PB - Brasil. Secretaria Municipal de educação RN. E-mail: josejailtonnribeiro@gmail.com 
ABSTRACT: The present article has the objective to identify and analyze some peculiarities about the training and professionalization their teaching practices. We also intend to investigate the issue of assumptions continuing education in Brazil, despite making an explanation of the practices already used in earlier times to present and elucidate the importance in having a continuing education for teachers. Identify the profile that was previously legacy to professional education as a priestly service, imposed by the Church, analyze the current model of teaching in their training process, connected mainly with new teaching practices and guidelines. Substantiate the historical process of professionalization of teaching, we tried to sketch an ideal teacher profile, the later decades with various social changes.

KEYWORDS: Teacher training. Training center. Theoretical and practical training articulated in initial and continuing education.

\section{Introdução}

Há cerca de 20 anos, por iniciativa de movimentos de educadores e, em paralelo, no âmbito do Ministério da Educação, iniciava-se um debate nacional sobre a formação de pedagogos e professores, com base na crítica da legislação vigente e na realidade constatada nas instituições formadoras.

O marco histórico de detonação do movimento pela reformulação dos cursos de formação do educador foi a I Conferência Brasileira de Educação realizada em São Paulo em 1980, abrindo-se o debate nacional sobre o curso de pedagogia e os cursos de licenciatura. A trajetória desse movimento destaca-se pela densidade das discussões e pelo êxito na mobilização dos educadores, mas o resultado prático foi modesto, não se tendo chegado até hoje a uma solução razoável para os problemas da formação dos educadores, nem no âmbito oficial nem no âmbito das instituições universitárias.

A discussão sobre a identidade do curso de pedagogia, que remonta aos pareceres de Valnir Chagas na condição de membro do antigo Conselho Federal de Educação, é retomada nos encontros do Comitê Nacional Pró-Formação do Educador, mais tarde transformada em Associação Nacional pela Formação dos Profissionais da Educação, e é bastante recorrente para pesquisadores da área. Estes já apontavam, em meados dos anos 80, a necessidade de se superar a fragmentação das habilitações no espaço escolar, propondo a superação das habilitações e especializações pela valorização do pedagogo escolar: 
O curso de pedagogia - sem entrar agora no mérito de sua função, isto é, de formar professores ou especialistas ou ambos - pouco se alterou em relação à Resolução no 252/69. Experiências alternativas foram tentadas em algumas instituições e o antigo Centro de Formação Educacional (CFE) expediu alguns pareceres sobre currículos experimentais, mas nenhum deles, a rigor, apresenta algo realmente inovador. Possíveis novidades no chamado curso de pedagogia seriam, por exemplo, a atribuição, ao lado de outras, da formação em nível superior de professores para as séries iniciais do Ensino Fundamental, supressão das habilitações (administração escolar, orientação educacional, supervisão escolar etc.) e alterações na denominação de algumas disciplinas.

Alterações geralmente inócuas, pois na maior parte dos casos foi mantida a prática da grade curricular e os mesmos conteúdos das antigas disciplinas, por exemplo, Organização do trabalho pedagógico manteve o conteúdo da anterior Administração escolar.

Em relação aos cursos de licenciatura, também não houve nenhuma mudança substantiva desde a Resolução no 292/62 do Centro de Formação Educacional (CFE), que dispunha sobre as matérias pedagógicas para a licenciatura. $\mathrm{O}$ que se tentou foram diferentes formas de organização do percurso da formação, umas mantendo o $3+1$ já presente em 1939, outras distribuindo as disciplinas pedagógicas ao longo do curso específico. Quanto ao local da formação pedagógica, em alguns lugares ela foi mantida nas faculdades de educação, em outros, foi deslocada, total ou parcialmente, aos institutos/departamentos/cursos.

\begin{abstract}
Atualmente, a atuação do Ministério da Educação e do CNE na regulamentação da LDB no 9.394/96 tem provocado a mobilização dos educadores de todos os níveis de ensino para rediscutir a formação de profissionais da educação. A nosso ver, não bastam iniciativas de formulação de reformas curriculares, princípios norteadores de formação, novas competências profissionais, novos eixos curriculares, base comum nacional etc. Faz-se necessária e urgente a definição explícita de uma estrutura organizacional para um sistema nacional de formação de profissionais da educação, incluindo a definição dos locais institucionais do processo formativo. Na verdade, reivindicamos o ordenamento legal e funcional de todo o conteúdo do Titulo VI da nova LDB (LIBÂNEO, 1999, p. 241).
\end{abstract}

Resumidamente, o disposto no Título VI da LDB (Lei de Diretrizes e Bases): 
a) Cursos de licenciatura plena para formar professores de educação básica, em universidades e Institutos Superiores de Educação:

- Curso Normal Superior (licenciatura para formar docentes de educação infantil e séries iniciais do Ensino Fundamental) e licenciaturas para formar professores de 5a a 8a e Ensino Médio);

- Programas de formação pedagógica para portadores de diplomas de educação superior;

- Programas de educação continuada.

b) Cursos de graduação e pós-graduação em pedagogia para formar profissionais da educação para administração, planejamento, inspeção, supervisão e orientação educacional:

c) Cursos de preparação para o magistério de Ensino Superior:

Segundo Severino (1999), pelo Edital no 4, de 3/12/97, a SESu/MEC designou comissões de especialistas para elaboração de diretrizes curriculares dos cursos superiores, incluindo as licenciaturas onde coubesse. Em 6/5/99, a Comissão de Especialistas de ensino de Pedagogia (designada pela Portaria SESu/MEC no 146, de março de 1998) tornou pública sua proposta de diretrizes curriculares para o curso de pedagogia. O mesmo órgão, por meio da Portaria nº 808, de 8/6/99 (LIBANEO, 1999 p. 42), designou um Grupo de Trabalho para elaboração das diretrizes curriculares para todas as licenciaturas, reconhecendo a necessidade de orientações normativas gerais para a parte curricular referente à formação pedagógica. Os debates ocorridos nesse GT (Grupo de Trabalhos) resultaram no Documento Norteador para a Elaboração de Diretrizes Curriculares para os Cursos de Formação de Professores (1999), já encaminhado à SESU. Todavia, foram manifestadas nas reuniões de trabalho diferentes posições sobre a formação dos profissionais da educação, não incluídas no corpo do referido documento. A meta deste texto é apresentar uma dessas posições, que expressa a proposta de um sistema nacional de formação dos profissionais da educação.

\section{A formação de professores da educação básica}

Paro (1988, p. 258) afirma que tem sido unânime a insatisfação de gestores, pesquisadores e professores com as formas convencionais de se formar professores em nosso país. Realizados em dois níveis de ensino - Médio e Superior -, os atuais cursos 
não dão conta de preparar o professor com a qualidade que se exige hoje desse profissional. No nível médio, realiza-se a formação dos professores das quatro séries iniciais do Ensino Fundamental e, em alguns casos, a formação dos professores para a educação infantil.

Conforme mencionamos anteriormente, essas modalidades de formação já demonstraram historicamente seu esgotamento em nosso país e em vários outros. A LDB institui, também, a possibilidade de que a formação dos professores para todos os níveis de escolaridade ocorra nos Institutos Superiores de Educação, não necessariamente universitários.

A partir de então, aceleram-se algumas alterações no cenário da formação de professores, o que aponta para a urgência de um posicionamento quanto à formação dos professores como profissionais da educação. As inovações curriculares interdisciplinaridade, sala-ambiente, ciclos de aprendizagem e outras - requerem dos professores novas exigências de atuação profissional e em consequência, surge novos saberes pedagógicos, que nem sempre tiveram lugar em sua formação.

A defesa de um local institucional específico para formar professores a atividade docente vem se modificando em decorrência de transformações nas concepções de escola e nas formas de construção do saber, resultando na necessidade de se repensar a intervenção pedagógico-didática na prática escolar. Um dos aspectos cruciais dessas transformações, os quais têm se evidenciado em avaliações educacionais.

Soares (1996, 1997 e 1998), diz que é o investimento na qualidade da formação dos docentes e no aperfeiçoamento das condições de trabalho nas escolas, para que estas favoreçam a construção coletiva de projetos pedagógicos capazes de alterar os quadros de reprovação, retenção e da qualidade social e humana dos resultados da escolarização.

A própria LDB no 9.394/96, em seu art. 62, estabelece como regra que a formação dos docentes para a educação fundamental e para a educação infantil far-se-á em nível superior. A elevação da formação docente em nível superior, reivindicação antiga dos educadores em nosso país e já consolidada em grande parte dos países desenvolvidos, fica assim contemplada.

\section{Que tipo de professor queremos formar?}

Na sociedade contemporânea, as rápidas transformações no mundo do trabalho, o avanço tecnológico configurando a sociedade virtual e os meios de informação e 
comunicação incidem na escola de forma positiva, aumentando os desafios para torná-la uma conquista $\mathrm{d}$

Segundo Silva (1999, p. 260) afirma que não se ignora que esse desafio precisa ser prioritariamente enfrentado no campo das políticas públicas. Todavia, não é menos certo que os professores são profissionais essenciais na construção dessa nova escola.

Já de acordo com Ramalho (2004):

Assumir a reflexão, a crítica, a pesquisa como atitude que possibilitam ao professor participar na construção de sua profissão e no desenvolvimento da inovação educativa, norteia a formação de um profissional não para compreender e explicar os processos educativos dos quais participa, como também para contribuir na transformação da realidade educacional no âmbito de seus projetos pessoais e coletivos (RAMALHO, 2004, p. 23).

O desenvolvimento profissional envolve formação inicial e contínua articuladas a um processo de valorização indenitária e profissional dos professores. Identidade que é epistemológica, ou seja, que reconhece a docência como um campo de conhecimentos específicos configurados em quatro grandes conjuntos, a saber, conteúdo das diversas áreas do saber e do ensino, ou seja, das ciências humanas e naturais, da cultura e das artes; conteúdos didático-pedagógicos (diretamente relacionados ao campo da prática profissional, conteúdos relacionados a saberes pedagógicos mais amplos (do campo teórico da prática educacional e conteúdos ligados à explicitação do sentido da existência humana individual, sensibilidade pessoal e sócia, considera, assim, que as transformações das práticas docentes só se efetivam na medida em que o professor amplia sua consciência sobre a própria prática, a da sala de aula e a da escola como um todo, o que pressupõe conhecimentos teóricos e críticos sobre a realidade. Em consequência, valorizar o trabalho docente significa dotar os professores de perspectivas de análise que os ajudem a compreender os contextos históricos, sociais, culturais, organizacionais nos quais se dá sua atividade docente. Em síntese, dizemos que o professor é um profissional do humano que: ajuda o desenvolvimento pessoal/intersubjetivo do aluno; um facilitador do acesso do aluno ao conhecimento (informador informado); um ser de cultura que domina de forma profunda sua área de especialidade. Esse profissional deve ser formado nas universidades devem ser contextualizando com o conhecimento prévio, que é o lugar da produção social do conhecimento, da circulação da produção cultural em diferentes áreas do saber e do permanente exercício da crítica histórico-social. 


\section{Centro de formação, pesquisa e desenvolvimento profissional de professores (CFPD)}

Um ponto de vista radical sobre essa questão leva ao enfrentamento do desafio da definição dos locais institucionais para a formação desses profissionais e de orientações explícitas sobre a organização curricular, assegurando um suporte legal de marcos institucionais e curriculares nacionais.

É preciso uma mudança radical nas formas institucionais e curriculares de formação de professores, superando o atual esquema do bacharelado e da licenciatura, que não responde mais às necessidades prementes de qualificação profissional para um tempo novo. As faculdades de educação têm sido, ao longo de décadas, local da produção do conhecimento sobre educação e ensino que, na maioria das vezes, tem sido ignorado pelos institutos/departamentos/cursos específicos.

Há que se considerar, ainda, a desigualdade de importância entre os saberes constitutivos da docência na formação dos professores, privilegiando aqueles relacionados às competências didático-pedagógicas do ensino (metodologias e práticas de ensinar), considerados de modo fragmentado e dissociados das áreas específicas e apenas disciplinares e os relacionados aos saberes pedagógicos mais amplos. Um centro específico de formação, pesquisa e desenvolvimento profissional de professores possibilitaria a superação da hoje dicotômica visão da docência.

Os professores que atuam nas séries finais do Ensino Fundamental em parte é a problemática e as questões essenciais da docência nos demais segmentos, o que traz problemas insuperáveis nos resultados do ensino e do processo formativo, pois seus profissionais operam a docência como um conjunto de "gavetas fragmentadas e justapostas", negando a característica de complexidade do fenômeno ensino (PIMENTA, 1996, p. 272).

Em que o CFPD avança na discussão sobre a formação de professores A institucionalização do CFPD possibilita a incorporação dos princípios que os educadores:

Introduz o conceito de desenvolvimento profissional, superando uma visão dicotômica da formação inicial e da formação contínua;

A formação é especialmente voltada para a profissionalidade docente e para a construção da identidade do professor. Experiências bem-sucedidas (especialmente as realizadas em alguns cursos de pedagogia) mostram que os cursos que se voltaram para tematizar a formação e o exercício da docência como objeto de formação e pesquisa 
podem se constituir em espaços mais férteis na produção de conhecimento e mais compromissados com a prática social da docência;

A formação de professores para qualquer um dos níveis de ensino no CFPD estará assentada na compreensão de que a escolaridade constitui um processo contínuo e uma totalidade, superando a atual fragmentação. Além disso, possibilitará que os graduados complementem e ampliem sua formação para atuar em diferentes níveis de ensino.

\section{Formação teórico-prática articulada na formação inicial e contínua}

As formações de professores apontam como questão essencial o fato de que os professores desempenham uma atividade teórico-prática. É difícil pensar na possibilidade de educar fora de uma situação concreta e de uma realidade definida. A profissão de professor precisa combinar sistematicamente elementos teóricos com situações práticas reais. Atualmente, em boa parte dos cursos de licenciatura, a aproximação do futuro professor à realidade escolar acontece após ele ter passado pela formação apenas teórica, tanto na disciplina especifica como nas disciplinas pedagógicas.

Para Ramalho (2008):

O profissional como figura histórica é sujeito de um processo histórico, que condensa todo um conjunto de condições, processos e práticas sociais em geral articuladas, por um lado, pela demanda social, e por outro, por um campo de conhecimentos estruturados. O profissional está sujeito à incidências dos diversos fatores, tais como: a conjuntura, posições e forças sociais, reorientação quanto ao tipo de demanda, formas de produção organização social, etc. (RAMALHO, 2008, p. 54).

Com isso, institui-se uma concepção de formação centrada na ideia de escola como unidade básica da mudança educativa, em que as escolas são consideradas "espaços institucionais para a inovação e a melhoria e, simultaneamente, como contextos privilegiados para a formação contínua de professores" (ESCUDERO; BOTIA 1994, p. 101-107).

\section{Sobre formar professores no curso de pedagogia}

Hoje no Brasil e expressa na LDB, de formação de professores para a educação infantil e as séries iniciais do Ensino Fundamental em nível superior, representa uma conquista dos educadores brasileiros, amplamente tematizada nas Conferências 
Brasileiras de Educação (CBEs), a partir de 1980 (ESCUDERO; BOTIA 1994, p. 101 107). Tem sido frequente nesses cursos tomar a prática docente como objeto de formação teórico-prática, contribuindo para ampliar o conhecimento no campo da formação de professores. Outros cursos mantiveram a formação dos professores de $1^{\mathrm{a}}$ a $4^{\mathrm{a}}$ série apenas como uma habilitação ao lado de outras.

Por outro lado, do mesmo modo que rejeitamos a redução do curso de pedagogia à formação de professores para a educação infantil e as séries iniciais do Ensino Fundamental, não nos pareceu oportuna a designação de Escola Normal Superior dada a esses cursos na legislação mais recente do Conselho Nacional de Educação, a argumentação que desenvolvemos até aqui acentua nossa posição contrária à extinção do curso de pedagogia, como também contrária à autonomização de uma Escola Normal Superior.

Desse modo, é lastimável que o CNE esteja legislando aos pedaços, levando à fragmentação da legislação e dos próprios cursos, desconsiderando a ideia de um sistema integrado e articulado de formação dos profissionais da educação e a rica investigação teórica produzida na universidade e nas escolas.

\section{A profissionalização de professores em um contexto histórico}

No final do século XVII, o Estado criou uma espécie de licença, momento este decisivo no processo de profissionalização docente. Os educadores eram funcionários de forma diferenciada, havendo uma intencionalidade política nos processos sociais aos quais estão envolvidos.

No contexto atual, ou seja, as primeiras décadas do século $\mathrm{XX}$ vive-se momentos de necessidade de renovação em todos os setores da sociedade, observa-se na área da educação esta necessidade, assim como de reflexão para praticas mais eficientes e eficaz.

Não tem como falar em educação de qualidade sem mencionar uma formação continuada de professores; que já vem sendo considerada, juntamente com a formação inicial, uma questão fundamental nas políticas públicas para a educação. O professor precisa também estar preparado para os novos e crescentes desafios desta geração que nunca esteve tão em contato com novas tecnologias e fontes de acesso ao conhecimento (o que inclui a internet), como hoje. 
Além disso, em sua formação inicial possivelmente houve alguns aspectos deficitários, pois, um exame do histórico da formação inicial em nosso país mostra que ela não vem sendo bem-sucedida na maioria das vezes.

Esta formação continuada, não se esgota somente em um curso de atualização, mas deve ser encarada como um processo, construído no cotidiano escolar de forma constante e contínua (CUNHA; KRASILCHIK, 2000, p.3).

A formação do professor vai além da aprendizagem de técnicas, conceitos e metodologias, requer um envolvimento maior com desenvolvimento curricular, planejamento e em tese a capacidade de solucionar problemas relacionados ao contexto escolar que surgirão futuramente.

\section{A formação docente}

Segundo o estudioso Perrenoud (2008), a formação profissional contínua se organiza em determinadas áreas prioritárias. Dentre elas estão as competências básicas que cabem ao educador. Refere - se como áreas de competências, devido cada uma delas abordar várias competências.

Contudo na capacitação profissional deve-se valorizar e incentivar o planejamento docente envolto a um professor facilitador da aprendizagem, estabelecendo estratégias de pensamento e de estímulo, sendo assim mais uma vez volta-se à importância da reflexão sobre a prática num contexto determinado.

Com relação à formação de professores, destacam-se vários aspectos que devem ser considerados neste processo: a necessidade de articulação entre a teoria e a prática, a valorização da atitude crítico-reflexiva na busca de autoformação, a valorização de saberes e práticas docentes, Nessa atividade de reflexão conjunta com o professor, estabelecesse um trabalho de cooperação na construção de recursos e estratégias de ensino a serem desenvolvidas pelo professor, incluindo a produção de materiais pedagógicos.

Segundo Freire (1997) a ideia de que ao professor se fazem necessárias uma sólida formação e uma ampla cultura geral, a fim de que possa lidar com os dados presentes na cultura do aluno - aqueles conhecimentos que trazem de outros lugares e de outras experiências, sua visão de mundo e as leituras que faz deste mundo.

Dessa forma podemos afirmar que estamos passando de uma lógica que separa os diferentes tempos de formação, existente dentro de nosso sistema educacional, para outra 
que percebe esse desenvolvimento profissional como um processo ao longo da vida do educador.

A valorização do professor pela sua formação adequada permitirá que ele tenha um papel central na aprendizagem do aluno e torne-se real representante da cidadania popular (é uma crítica à concepção autoritária de cidadania no tratamento da legitimação para a propositura da ação popular) tão almejada nos últimos tempos pelo mercado de trabalho, que busca no incentivo de uma educação de qualidade a melhor estratégia para maior produtividade.

O educador pode ter referência importante por meio dos quatro pilares da educação.

- Aprender a conhecer: este tipo de aprendizagem visa o domínio dos próprios instrumentos de conhecimento, necessários para se viver dignamente, para desenvolver as capacidades profissionais e para a comunicação. Em outras palavras, seu fundamento é aprender a aprender;

- Aprender a fazer: esta aprendizagem está mais ligada à questão da formação profissional, em que prepara as pessoas para enfrentarem numerosas situações e a trabalharem aprender a fazer: esta aprendizagem está mais ligada à questão da formação profissional, em que prepara as pessoas para enfrentarem numerosas situações e a trabalharem em equipe;

- Aprender a viver juntos: desenvolver consciência das semelhanças e da interdependência entre todos os seres humanos, para que juntos possam realizar projetos e resolver conflitos, com a tendência de gerar a paz;

- Aprender a ser: educação que deve contribuir para o desenvolvimento total da pessoa, nos seguintes sentidos: (espírito e corpo, inteligência, sensibilidade, estético, responsabilidade pessoal e espiritualidade) que ensinam a agir nas várias circunstâncias da vida. (KULLOK, 2009, p. 46).

A competência de envolver os alunos em sua aprendizagem e em seu trabalho discute a democratização dos estudos e a motivação dos alunos em face aos estudos. Conceitua o ensinar como um reforço à decisão de aprender. Ensinar também seria estimular o desejo do saber. 


\section{A formação continuada no Brasil}

Fazendo um pequeno desvio histórico sobre a formação de professores no Brasil, lembramos que a formação de docentes para o ensino das primeiras letras que foram Estratégias utilizadas pelos intelectuais, e políticos para organizar do ensino e um modelo escolar de transmissão de conhecimento, articulação a questão da implantação de novos métodos de ensino que procuraram romper com o ensino individual e a necessidade de formação dos professores em cursos específicos foi proposta no final do século XIX com a criação das Escolas Normais.

Podemos dizer que a formação dos professores ainda e algo autônomo que ainda depende só da busca deles por melhores condições de ensino. Para Garcia (1999), até os anos 1990, a produção científica sobre formação docente estava incluída no campo da Didática. O autor toma certamente como referência o seu país de origem, a Espanha, para fazer essa afirmação, mas podemos dizer que no Brasil não foi diferente.

$\mathrm{Na}$ história da formação docente no Brasil, verificamos que o primeiro modelo predominou nas universidades e demais instituições de Ensino Superior que se encarregaram da formação dos professores secundários, ao passo que o segundo tendeu a prevalecer nas escolas normais, ou seja, na formação dos professores primários. Vale ressaltar que a investigação sobre a formação de professores no início do século $\mathrm{XX}$ centra-se mais nas políticas educacional no currículo e no estatuto dos cursos de licenciatura, especialmente do curso de Pedagogia.

No Brasil a questão do preparo de professores emerge após a independência, quando se cogita da organização da instrução popular.

Os professores estão, na sua esmagadora maioria, agudamente conscientes da inadequação da formação profissional recebida; eles se sentem desatualizado e sem que ninguém esteja preocupado com a formação continuada para um melhor ensino de qualidade.

A formação de professores entendida como um continuo, ou seja, como um processo de desenvolvimento que acontece por toda a vida (MIZUKAMI, 2002), amplia a concepção de formação considerada como conjunto de momentos formais na formação inicial ou como sinônimo de eventos com caráter de reciclagem ou capacitação, que prevaleceram até há pouco na história da Educação. O professor não é um técnico especialista que aplica o conhecimento científico às situações da escola e da sala de aula. 
A formação do aluno é complexa e envolve objetivos profissionalizantes, tratando também do seu desenvolvimento pessoal.

A reflexão implica uma tentativa de imersão consciente do homem no mundo da experiência. O conhecimento teórico só pode ser instrumento de reflexão se for integrado ao esquema de pensamentos ativados pelo indivíduo ao interpretar a realidade.

O professor hoje não tem tempo para colocarem sua formação para e isso dificulta muito sua pratica nas salas de aula. Muitos professores não têm tempo para planeja suas aulas como terão tempo para ser atualiza para busca, mas conhecimentos, são pequenos detalhes que podem muda a história da educação no Brasil.

\section{A formação continuada para professores do ensino fundamental}

A formação continuada de professores, de acordo com os novos olhares expressos pela LDB 9394/96, veio abordando importantes valores no sentido de qualificar o trabalho docente visando ao alcance de melhores níveis de aprendizado na escola brasileira. No entanto, ela requer amplas reflexões no sentido de mudar as condições de trabalho impostas aos professores na educação brasileira.

As questões ligadas ao processo de formação do professor na sociedade brasileira exigem novos olhares a respeito dos currículos formadores das instituições de ensino, como também é preciso redimensionar o papel de participação social do professor Para uma formação de qualidade, o professor procura renovar sua prática pedagógica em busca de um ensino de melhor eficiência que resultará na transformação de sua ação docente.

A capacitação do docente, quando envolvente e compromissada, poderá proporcionar um desenvolvimento de novas competências para que o professor busque uma inovação pedagógica e, sobretudo num ensino de qualidade. Uma educação de qualidade, onde o coletivo supera o isolamento de práticas estereotipadas que não buscam construir uma nova sociedade saudável e uma educação de qualidade. A formação continuada não é algo eventual, nem apenas um instrumental destinado a suprir deficiências de uma formação inicial malfeita ou de baixa qualidade, ao contrário, deve ser sempre parte integrante do exercício profissional do professor. Essa perspectiva leva a afirmar a necessidade de transformar o modo como se dão os diferentes momentos da formação do professor, desde a inicial até a continuada, nesse caso percebe-se a presença de um sistema de desenvolvimento profissional integrado em diferentes momentos.

Para Ramalho: 
A problemática da preparação do professorado, seja para atuar nas series iniciais do sistema de ensino, seja para atuar em outros níveis educacionais, é motivo de diversas, aprofundadas e complexas discussões no Brasil. Essas discussões emergem de uma profunda crise na preparação desse profissional, crise que não é só organizacional, curricular ou social que, se bem que determinantes, estão relacionados com a própria definição da identidade profissional. (RAMALHO, 2004, p. 105).

O professor iniciante na carreira se depara com inúmeras responsabilidades de sua atuação e se diferencia do professor mais experiente quando ainda não consegue refletir sobre a sua prática, e a faz apenas a partir das bases que suas atribuições lhe expressam. Nesse caso, o professor iniciante tem a possibilidade de desenvolver a reflexão, a compreensão, interpretação e capacidade de intervir na realidade educativa; este pode ser o início de uma atuação, período no qual o professor novo se integra como membro ativo e participante profissionalmente. A competência profissional do professor é obtida no momento que o conhecimento é apropriado por ele dialeticamente possibilitando articular os saberes segundo o quadro social que se estabelece.

O conhecimento nas variadas dimensões assumidas no trabalho que o professor executa no contexto educacional, revela-se como importante referencial a ser explorado, pelos sujeitos que se candidatam ao ofício de professor, constituindo-se o exercício profissional como um amplo leque de possibilidades de obtenção do conhecimento da realidade que os sujeitos se inserem historicamente.

\section{Metodologia}

Segundo a conceitualização de Biderman (1998), afirma que metodologia é o estudo dos métodos a serem empregados ao se ensinar uma ciência ou uma arte, conjunto de métodos empregados em uma atividade. Portanto, com base neste contexto nos propomos a descrever o caminho realizado em nossa pesquisa.

A pesquisa foi elaborada através de levantamentos bibliográficos, consulta documental em banco de dados oficiais, nos últimos 30 dias.

Sobre as bases de dados para o Levantamento bibliográfico:

a) Pesquisa na base da Biblioteca Virtual em educação: foi utilizada, busca na literatura científica e técnica da área "Ciências da Saúde em Geral”, cuja captação reúne as seguintes bases:

-Portal do MEC: 


\section{- Biblioteca da UFRN}

- Biblioteca da Faculdade Mauricio de Nassau - RN

- SciELO - Scientific Electronic Library Online: é um projeto consolidado de publicação eletrônica de periódicos científicos seguindo o modelo de Open Access, que disponibiliza, de modo gratuito, na Internet, os textos completos dos artigos de mais de 290 revistas científicas do Brasil, Chile, Cuba, Espanha, Venezuela e outros países da América Latina. Além da publicação eletrônica dos artigos, SciELO provê enlaces de saída e chegada por meio de nomes de autores e de referências bibliográficas. Também publica relatórios e indicadores de uso e impacto das revistas.

\section{Considerações Finais}

Mesmo diante tudo que foi exposto neste artigo, ainda há uma necessidade de discutir sobre a formação dos educadores, onde essa discussão abriu-se um debate nacional sobre os cursos de pedagogia e as diversas licenciaturas, contudo o resultado mostrado ao logo desde trabalho não chegamos a uma solução razoável para elucidar os problemas da formação dos professores.

Visto que em um contexto histórico passamos muito tempo sem avanço nos processos de formação e profissionalização docente. Não bastam apenas iniciativas e sim novo eixo curricular para se desenvolver novas competências profissionais, como também reconstruir novas competências e habilidades educacionais em nossos Professores.

A formação do professor deve ter como base a docência, colocando em debate na contramão das necessárias mudanças na formação do professor em que o trabalho pedagógico não pode ser constituir-se em algo imutável, pois as novas realidades estão exigindo um amplo entendimento das práticas educativas, onde foi preciso anos para desenvolver novas técnicas e práticas, a fim de conscientizar as pessoas incentivar assembleias, reuniões e formas de desenvolver novas gestões.

A educação acontece em diversos âmbitos, em muitas instâncias formais, não formais e informais; a educação ocorre tanto em casa como em qualquer outro lugar não se fazendo necessário somente nas escolas.

É importante se ter um bom professor com uma formação de qualidade, onde o desenvolvimento profissional envolve formação inicial e continuada com a valorização 
do pedagogo, não é qualquer um que pode ser professor e sim aquele que tem competência para exercer a função.

O bom profissional deve ser formado em uma universidade deve ter conhecimentos prévios em diferentes áreas do saber, em que devemos atribuir uma importância maior para a educação continuada, onde a educação deve ser intencional renovadora em práticas educativas dos saberes, construindo novas competências em que o professor construa junto com os alunos, e construir com eles os saberes didáticos necessários para o processo de ensino e aprendizagem.

Infelizmente a formação do professor ainda é muito frágil no Brasil, na atualidade existem muitos meios para que os professores se especializem porem os mesmos não tem tempo para isso ou até mesmo motivação, geralmente trabalham três horários para poder ter uma renda adequada para sobreviver e fazer o próprio investimento em sua formação docente.

\section{REFERENCIAS}

ANFOPE. Documentos finais de encontros. 1983-92.

BERNARDO, M. V. C. O surgimento e a trajetória da formação do professor secundário nas universidades estaduais paulistas. In: BERNARDO, M.V. C. (org.). Formação do professor: Atualizando o debate. São Paulo: Educ, 1989.

BIDERMAN M. T. C. Dicionário didático de português. São Paulo, Ática, 1998.

CANDAU, V. M. (Coord.). Novos rumos da licenciatura: pesquisa. Brasília: Inep/PUC-RJ, 1987.

CARVALHO, A. M. P. de. Identidade profissional do pedagogo: introduzindo o debate. In: Estudos e documentos (FE-USP), São Paulo, v. 36, 1996.

CUNHA, A. M. O. As concepções das crianças, adolescentes e adultos sobre as doenças infecciosas. São Paulo: Universidade de São Paulo. Faculdade de Educação. 2000. (Dissertação de Mestrado).

ESCUDERO, J. M.; BOTIA, B. Inovação e formação centrada na escola. Uma perspectiva da realidade espanhola. In: AMIGUINHO, A.; CANÁRIO, R. (Orgs.). Escolas e mudança: o papel dos Centros de Formação. Lisboa: Educa, 1994.

FREIRE, P. Pedagogia da autonomia: saberes necessários á prática docente. Rio de Janeiro: Paz e Terra, 1997.

GARRIDO, E.; FUSARI, M. F. R.; MOURA, M. O.; PIMENTA, S. G. Projeto USPAyres/FE-USP/Fapesp: A pesquisa colaborativa, a formação do professor reflexivo: 
investigativo e a construção coletiva de saberes e práticas pela equipe escolar. IN: Anais do IX Endipe - Encontro Nacional de Didática e Prática de Ensino. Águas de Lindóia, vol. 1, 1998, p. 48-49.

KULLOK, M. G. B. As exigências para formação do professor da atualidade. São Paulo: Edufal, 1998.

LIBÂNEO, J. C. Pedagogia e pedagogos, para quê? São Paulo: Cortez, 1998.

LIBÂNEO, J. C. Adeus professor, adeus professora? In: Novas exigências educacionais e profissão docente. São Paulo: Cortez, 1998.

LIBÂNEO, J. C. Prefácio. In: LIBÂNEO, J. C. Pedagogia e pedagogos, para quê? São Paulo: Cortez, 1998.

LIBÂNEO, J. C. Que destino os educadores darão à pedagogia?. In: PIMENTA, S. G. (Coord.). Pedagogia, ciência da educação? São Paulo: Cortez, 1996.

LIBÂNEO, J. C. Didática. São Paulo: Cortez, 1999.

LÜDKE, M. Avaliação institucional: formação de docentes para o ensino fundamental e médio (As licenciaturas). In: Cadernos CRUB, n. 4. Brasília, set. 1994.

MIZUKAMI, M. G. N. et al. Escola e aprendizagem da docência. São Carlos: Edufscar, 2002.

PARO, V. Administração escolar. São Paulo: Cortez, 1988.

PIMENTA, S. G. O pedagogo na escola pública. São Paulo: Loyola, 1988.

PIMENTA, S. G. Panorama atual da didática no quadro das ciências da educação: Educação, pedagogia e didática. In: PIMENTA, S. G. (Coord.). Pedagogia, ciência da educação? São Paulo: Cortez, 1996.

PIMENTA, S. G. Para uma re-significação da didática: Ciências da educação, pedagogia e didática, uma revisão conceitual, uma síntese provisória. In: PIMENTA, S. G. (Org.). Didática e formação de professores: percursos e perspectivas no Brasil e em Portugal. São Paulo: Cortez, 1997.

PIMENTA, S. G. Formação de professores: saberes e identidade da docência. In: PIMENTA, S. G. (Org.). Saberes pedagógicos e atividade docente. São Paulo: Cortez, 1999.

RAMALHO, B. L. et al. Formar o professor, profissionalizar o ensino: perspectivas e desafios. 2 ed. Porto alegre: Sulina, 2008.

GOVERNO DO ESTADO DE SÃO PAULO. Relatório Final da Comissão Especial para desenvolvimento de estudos sobre a formação dos profissionais da Educação no Estado de São Paulo (Conselho Estadual de Educação/SP). In: Revista de Educação, n. 10. São Paulo: Apeoesp, abr. 1999. 
SEVERINO, A. J. Minuta do documento norteador para elaboração das diretrizes curriculares dos cursos de licenciatura (Segunda versão). In: Documento apresentado ao GT-Licenciaturas da SESu- MEC, 1999. Não publicado.

SEVERINO, A. J. (Coord.). Documento norteador para elaboração das diretrizes curriculares para os cursos de formação de professores. SESu/MEC, set. 1999.

SILVA, C. S. B. Curso de pedagogia no Brasil: história e identidade. Campinas: Autores Associados, 1999.

SILVA, J. R.; CELESTINO A. Supervisão da educação: do autoritarismo ingênuo à vontade coletiva. São Paulo: Loyola, 1985.

\section{Como referenciar este artigo}

RIBEIRO, Jose Jailton. Formação e profissionalização docente: uma perspectiva de mudança. Temas em Educ. e Saúde, Araraquara, v.13, n.2, p. 242-259, jul./dez. 2017. Disponível em: <https://doi.org/10.26673/rtes.v13.n2.jul-dez.2017.9600>. E-ISSN: 2526-3471.

Submetido em: 25/03/2017

Aprovado em: 20/10/2017 